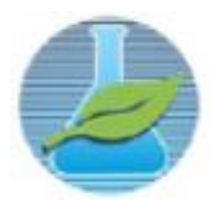

Vol. 03 N. 01 (2017) 037-039
JCEC/REQ ${ }^{2}$

Journal

ISSN: 2446-9416

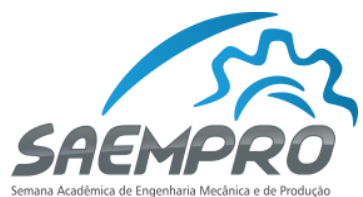

"EU, A INDÚSTRIA E O MUNDO"

08 a 11 de novembro de 2016 no campus Viçosa da UFV

Departamento de Engenharia de Produção e Mecânica - DEP

Universidade Federal de Viçosa - UFV

\title{
ESTUDO DE CASO DO SISTEMA DE ABASTECIMENTO E DISTRIBUIÇÃO DE ÁGUA DA CIDADE DE VIÇOSA-MG
}

\author{
Felipe Mendes Martins \\ Universidade Federal de Viçosa, Departamento de Engenharia de Produção e Mecânica \\ $\mathrm{Ph}$. Rolfs s/n - 36570-000 - Viçosa - MG \\ martins.felipemendes@gmail.com
}

\section{INTRODUÇÃO}

Os sistemas de abastecimento de água compõem uma importante parte da sociedade. O seu principal objetivo é garantir a distribuição de água em qualidade e quantidade suficiente para atender as necessidades básicas dos habitantes. Os estudos das redes existentes, e a elaboração de projetos novos é uma tarefa complicada, pois envolve cálculos complexos de mecânica dos fluídos. Sendo assim, o uso computacional para estes cálculos se tornou uma ferramenta importante. E neste contexto, se encaixa o EPANET. Ele é um software para simulação da rede de distribuições de água de domínio público, criado pela EPA - Environment Protection Agency, que fornece como resultado as pressões nos nós e a vazão nos tubos.

É nesta conjuntura que este trabalho é proposto, ao criar uma rede para ser simulada através do EPANET e analisar o sistema de abastecimento da cidade de Viçosa-MG, propondo melhorias para o Sistema Autônomo de Água e esgoto (SAAE) e a otimização da utilização dos conjuntos motor-bomba e posterior redução com o gasto energético.

\section{OBJETIVO}

Este trabalho tem como principal objetivo criar uma rede do atual sistema de distribuição de água na cidade de Viçosa-MG, utilizando o EPANET, com o intuito de propor melhorias e economizar energia dos conjuntos motores-bombas.

\section{METODOLOGIA}

Os trabalhos devem conter no máximo 3 páginas em papel formato $\mathrm{A} 4 \mathrm{com}$ margens de $2 \mathrm{~cm}$ de cada lado, com exceção da primeira página que deve ter margem superior igual a $6 \mathrm{~cm}$ para o cabeçalho.

A modelagem da rede real é importante para que os resultados que serão obtidos estejam condizentes com a realidade. Sendo assim, a primeira parte deste trabalho foi importar a rede existente modelada em AUTOCAD ${ }^{\circledR}$ para o EPANET. Os dados importados foram às coordenadas dos nós e o traçado da rede de distribuição.

Já dentro do programa de simulação hidráulica, foi necessário introduzir os reservatórios, bombas e válvulas existentes, além de dados dos nós da rede e das tubulações complementares para que a simulação ocorra adequadamente. Estes seguem listados abaixo.

- Consumo nos nós

- Cota de nós e reservatórios;

- Altura mínima e máxima dos reservatórios; 
- Diâmetros dos reservatórios;

- Rugosidade e diâmetro dos tubos;

- Curvas das bombas (QxH e Qxך)

- Tarifas de energia para as bombas;

- Padrões temporais (Variação do consumo nos nós).

Após esta etapa, o modelo estará apto para as simulações que foram feitas ao longo de 24 horas e seguindo o esquema apresentado na Fig. 1.

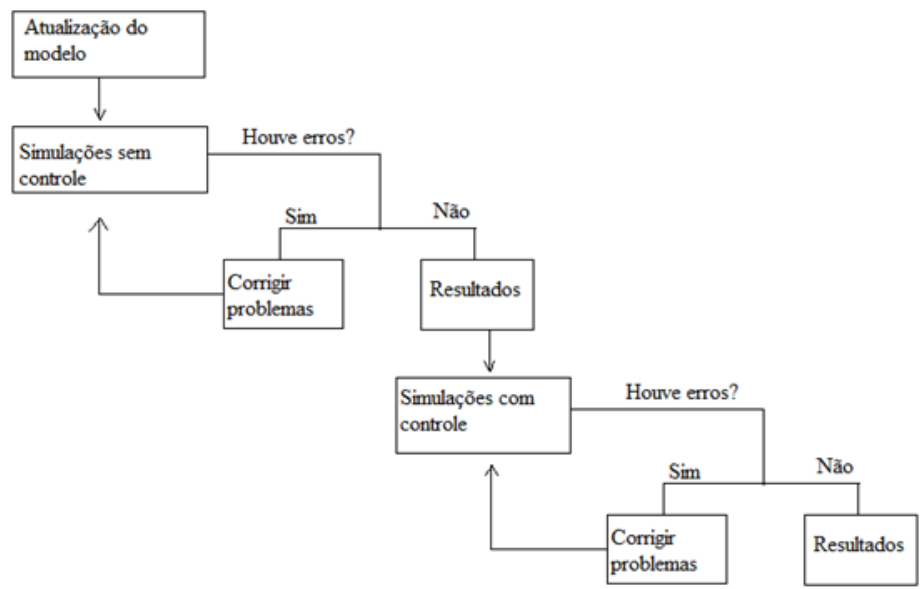

Figura 1 - Esquema metodológico de como foram feitas as simulações.

As opções de controle são utilizadas para ligar e desligar as bombas. Elas podem ser controladas por altura do nível de água do reservatório, por horário ou combinação dos dois.

\section{RESULTADOS}

A criação do modelo hidráulico resultou em uma rede de 2745 nós, 21 reservatórios, 2878 tubos, 11 bombas e 7 válvulas redutoras de pressão. Ao simular esta rede, foram encontrados alguns erros que foram posteriormente corrigidos. Na Fig. 2 se encontra a rede com as pressões encontradas nos nós como resultado da simulação às 11 horas.

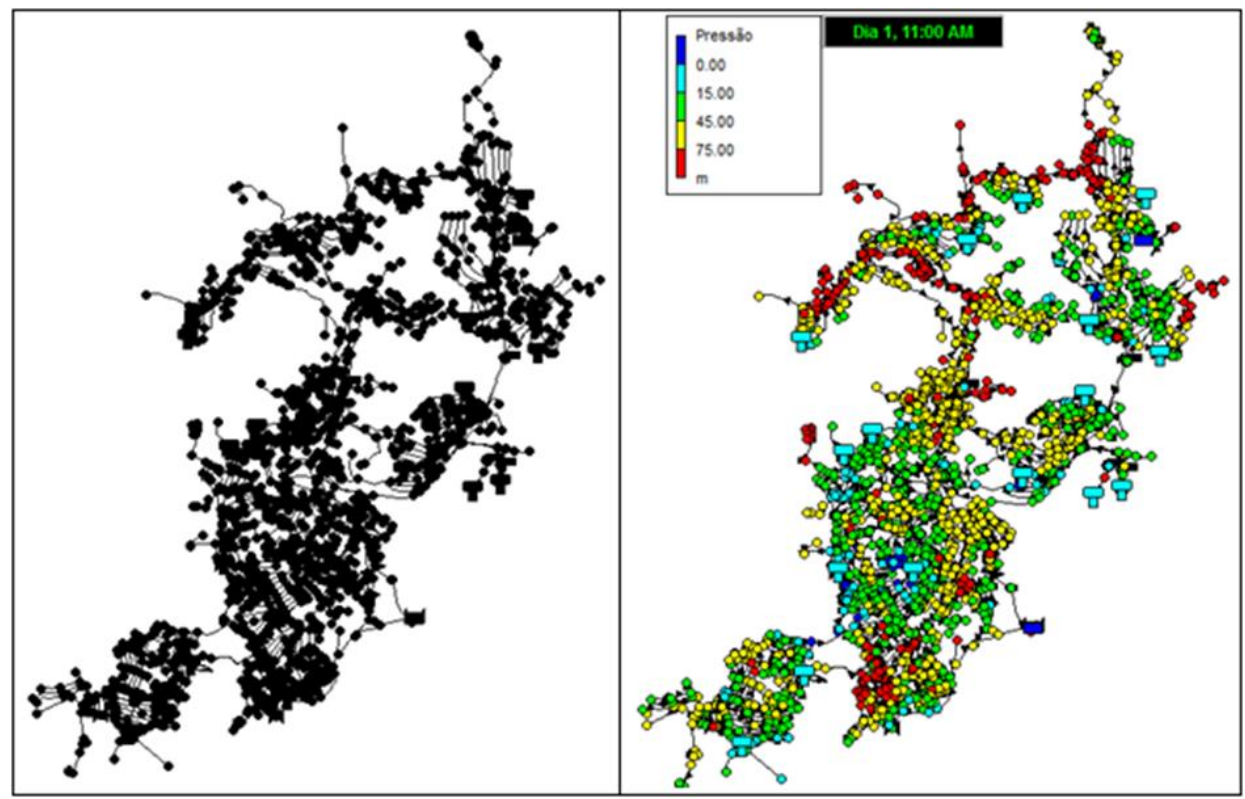

Figura 2 - Rede final elaborada e as pressões encontradas as 11 horas. 
Sem a utilização das opções de controle, as bombas são utilizadas durante toda a simulação, como visualizado na Fig. 3.

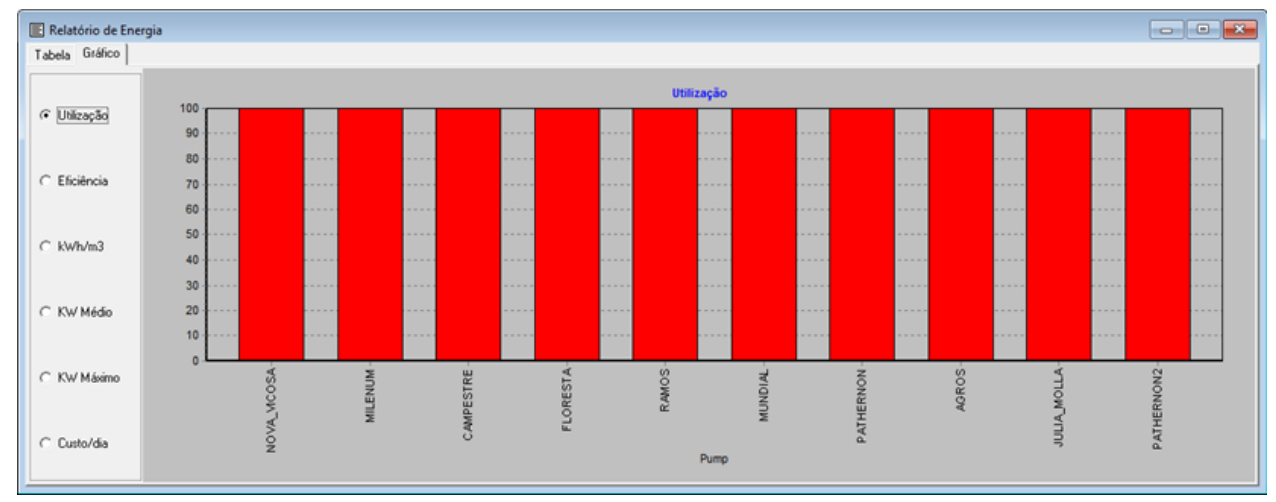

Figura 3 - Utilização das bombas sem controle.

Já com a utilização de parâmetros de controle, utilizado inicialmente para a bomba denominada MUNDIAL, obteve-se uma redução na utilização e consumo de energia da mesma, de 100\% para aproximadamente 75\%, representada na Fig. 4.

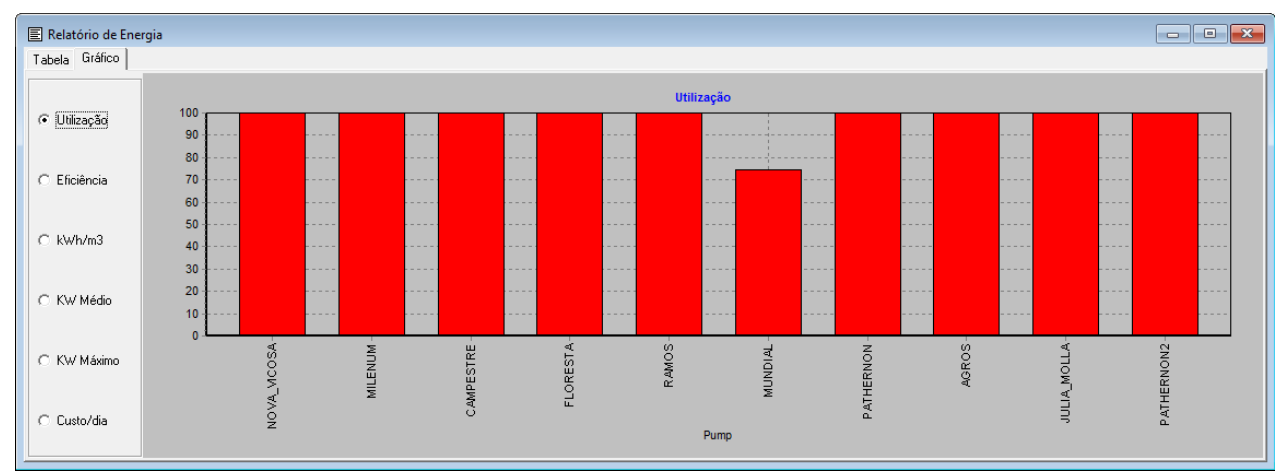

Figura 4 - Utilização das bombas com controle na bomba MUNDIAL.

O trabalho ainda está em desenvolvimento para as outras bombas com uma análise mais profunda e levantamento de dados faltantes.

\section{CONCLUSÃO}

As dificuldades encontradas para resolver os erros de simulação foram acima do esperado. Haviam nós sobrepostos e tubulações em que os nós não faziam parte da rede. Assim a primeira parte, a elaboração da rede de distribuição de água da cidade de Viçosa está completa, enquanto a segunda parte, de propor uma otimização para a utilização das bombas ainda está sendo desenvolvido.

Ela demanda de uma análise completa da rede, para que não ocorra falta d'água e ainda de possíveis simulações com tempos maiores, para que os resultados possam ser melhor observados. Contudo os resultados que são esperados com o controle e possíveis melhorias da rede irão reduzir o consumo de energia e melhorar a distribuição de água para a população.

\section{REFERÊNCIAS}

CASTRO, R. C. "Estudo do abastecimento da cidade de Pradópolis -SP, utilizando o programa EPANET”. Ribeirão Preto, 2011 Trabalho de Conclusão de Curso em Engenharia Ambiental Centro Universitário UNISEB. Ribeirão Preto- SP.

HENN, E. A. L. "Máquinas de fluido" - 2.ed. Santa Maria: Ed. Da UFSM, 2006. 
TSUTIYA, M. T. “Abastecimento de Água”. Departamento de Engenharia Hidráulica e Sanitária da Escola Politécnica de São Paulo, São Paulo, 2006. 